\title{
FNEP: Finnish-Nepalese Project for improving the meteorological readiness in Nepal
}

\author{
Antti Mäkelä ${ }^{*}$, Irma Ylikangas ${ }^{1}$, Ramchandra Karki ${ }^{2}$, Kamal Prakash Budhathoki ${ }^{2}$, \\ Adriaan Perrels ${ }^{1}$, Kristiina Säntti ${ }^{1}$, Mikko Partio ${ }^{1}$, and Matti Keränen ${ }^{1}$ \\ 1 Finnish Meteorological Institute (FMI) \\ 2 Department of Hydrology and Meteorology of Nepal (DHM)
}

\begin{abstract}
The Finnish Nepalese Project (FNEP) is a project aimed for the development of infrastructure, education and preparedness to better respond to the increased risks related to the weather-related natural disasters by climate change in Nepal. The project duration was 2010-2012, and the partners were the Finnish Meteorological Institute and the Government of Nepal, Ministry of Environment and Science, Department of Hydrology and Meteorology. The project is financed by the Finnish Ministry of Foreign Affairs. This paper introduces the concept and main results of the project.
\end{abstract}

Key words: Climate change, natural disasters, meteorology, Finnish-Nepalese Project (FNEP)

\section{INTRODUCTION}

The topography and climate of Nepal are extremely unique: the southern parts of the country lies only some hundreds of meters above sea level, while the Himalayan Mountains in the north reach upto 8848 meters above sea level. This highly variable topography has also large influence to the climate. Nepal is under the influence of monsoon circulation pattern, which means a pronounced cold and dry winter season followed by an extreme precipitation season with heat and moisture (Robinson and Henderson-Sellers, 1999). In Nepal, the monsoon precipitation season is from June until September. The average annual precipitation is about 1500-2000 millimeters (Malla, 2008), but may locally even reach up to 5000-6000 millimeters.

Recently, it has been noted that developing countries like Nepal are highly vulnerable to the effects of climate change (Malla, 2008; Xu et al., 2009). The main reasons for this are the poor infrastructure and the deficiencies in the monitoring, forecasting and giving warnings regarding especially the extreme weatherrelated phenomena. For example, in developed countries it is nowadays a relatively easy task to monitor intense convective phenomena in real time, and to provide warnings to citizens and authorities with high accuracy. Unfortunately, these kinds of tools and methods are largely lacking from the developing countries, although these countries are often the ones experiencing the most violent natural hazards. For example, lightning kills annually about 50 persons in Nepal, and landslides due to convective rain destroys roads and houses.

To properly understand the variation of weather in Nepal, the key issues are (1) to have a decent

Project manager:. Irma Ylikangas, FMI, P.O.Box 503, FIN-00101,Helsinki, Finland. E-mail:irma.ylikangas@fmi.fi

*Corresponding author: A Mäkelä, FMI, P.O.Box 503, FIN-00101, Helsinki, Finland. e-mail: antti.makela@fmi.fi 
number of reliable meteorological observations, and (2) to have enough trained people to perform and analyze the observations and to maintain the observation networks. By fulfilling these two tasks, there is a good basis for weather monitoring and forecasting. Furthermore, the sufficient amount and variety of observations, for example surface and upper atmospheric weather observations enable the more accurate description about the actual climate and its variations.

This paper introduces the concepts, benefits and results of an interactive project between two national meteorological and hydrological institutes, the Department of Hydrology and Meteorology of Nepal (DHM) and the Finnish Meteorological Institute (FMI).

\section{FNEP BACKGROUND AND MOTIVATION}

The motivation of the Finnish-Nepalese Project (FNEP) is to improve the capability of the governments of Nepal to respond to the increased risks related to the weather-related natural disasters by climate change. The project started in February 2010 and ended in the end of December 2012. The project budget was about $€ 500000$ and it has been financed by Finnish Ministry of Foreign Affairs (MFA). The project partners and participating institutes have been the Government of Nepal, Ministry of Environment and Science, DHM and FMI.

The backbones of FNEP have been capacity building of DHM personnel through trainings and the installations of new meteorological equipment and meteorological data management system. There have been hands on trainings of DHM meteorologists to use and maintain the new meteorological equipment and to exploit the data. For example, the implementation of a lightning location visualization software at the Tribhuvan International Airport was followed by a five-day hands on training. The smaller training sessions (1-3 days) concentrated into basics of a socio-economic study. Total of 57 DHM persons participated in trainings in Nepal. The trainings have been arranged during study tours in Finland. A total of 15 persons from DHM participated to the five study tours; the durations of the study tours varied from 1-2 weeks each.

The overall objective of the FNEP is to improve capability of Nepal to respond to the increased risks of natural disasters related to weather and climate. The project goal is to increase DHM capacity in hydro-meteorological observations, services and international data sharing.

\section{PROJECT RESULTSAND HIGHLIGHTS}

\subsection{Socio-economic scan}

The weather-related socio-economic impacts in Nepal are large (Figure 1). Therefore the goals of the socio-economic study in FNEP were to (a) identify most significant sectors and service needs in terms of total benefits from improved weather services, and (b) provide an estimate of the benefits of selected weather services for selected sectors.

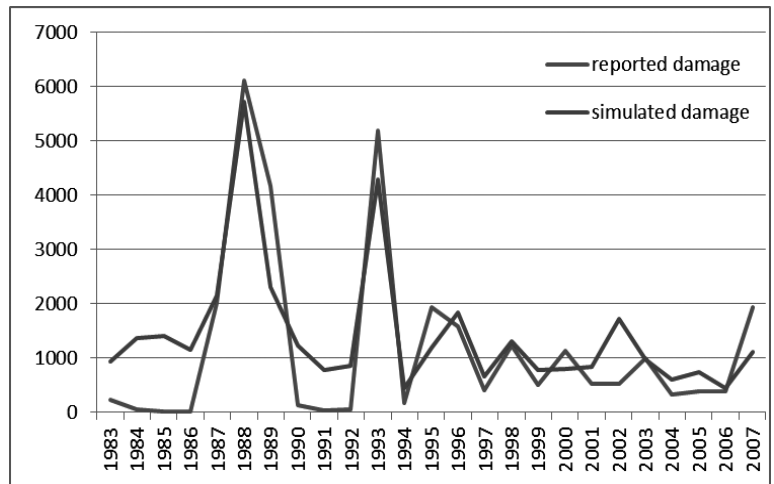

Figure 1: Reported damage value of extreme weather (million rupees) and its approximation by means of physical loss figures (homes and casualties). Source: Nepal Environmental Statistics and Perrels (2012).

Six sectors were included in this study: agriculture, energy, aviation, public health, tourism and road transport. Social-economic 
net benefits are most probably excellent. For example, the agricultural sector would benefit from improved ( 2 days ahead of the incident) weather forecasts by approximately 800 million rupees annually (about $€ 8$ million) because of the secured harvests of paddy rice and cereals. Saving of livestock and cash crops represents additional significant benefits (Perrels, 2011).

\subsection{Reliable hydro-meteorological observation network}

To be able to reach the benefits of the socio economic scan, a fully operational hydrometeorological observation network is needed (Poutiainen et al., 2011). The network itself is not enough, but there is also a need to manage the hydro-meteorological data and then further develop the data to products like weather forecasts, flood warnings, hazardous weather phenomena warnings (hail, gusts, lightning etc). The upgrading of the weather station network has taken the first step in the FNEP project. A new modern weather station was inaugurated during the World Meteorological Day (March 23rd 2012) at the Pokhara Airport (Figures 2 and 3). The new station transmits data in near real time to the new data management system at Tribhuvan International Airport. The data can then be further used to numerical weather model input to provide weather forecasts or any other services. The current weather information is available on a display to all airport passengers at Pokhara. In addition, three existing weather stations in the Kathmandu valley were upgraded to send real time data to the new data management system (Figure 2).

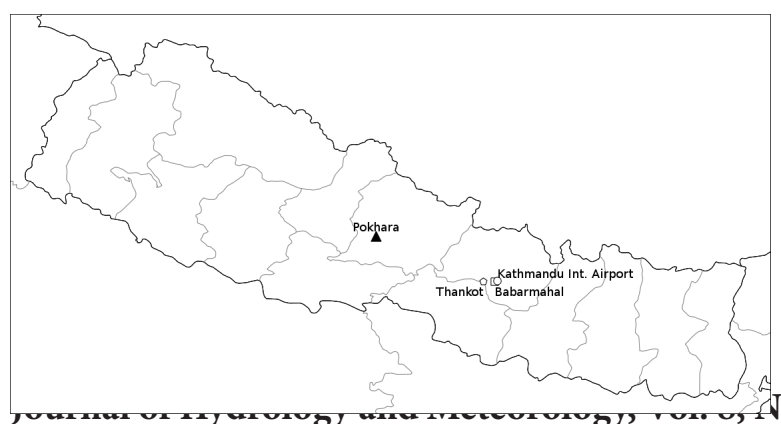

Figure 2: The locations of the automatic weather stations installed (Pokhara) and updated (Kathmandu airport, Thankot and Babarmahal) during FNEP.

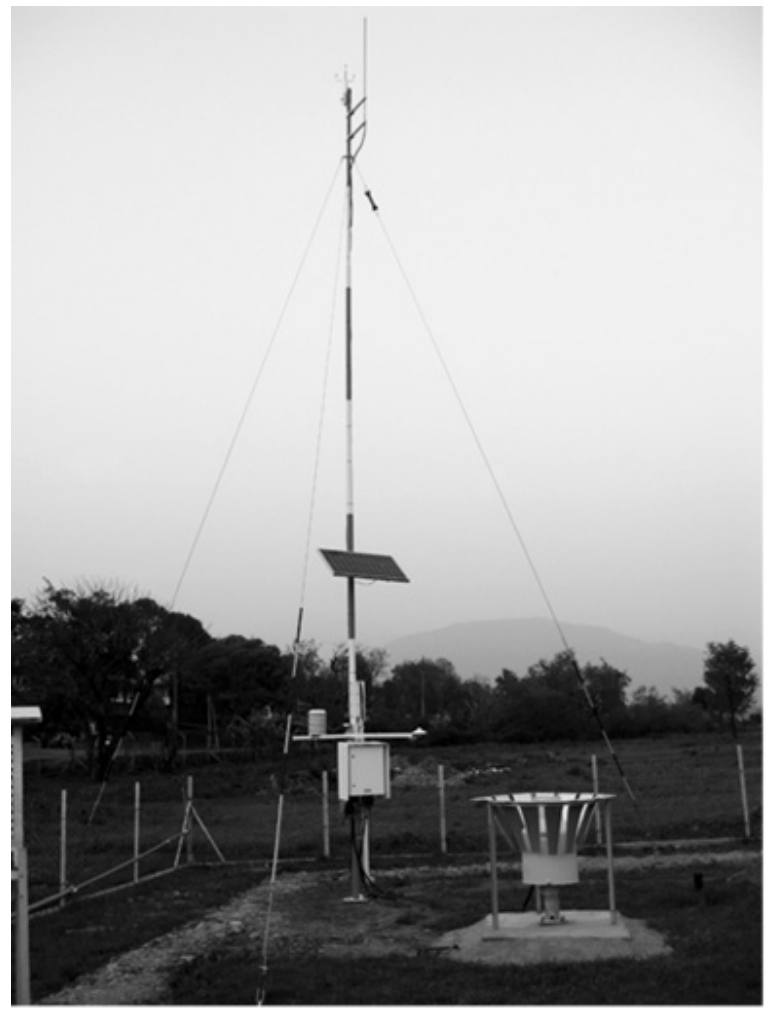

Figure 3: The automatic weather station installed in Pokhara during FNEP.

\subsection{Quality Control and Data Management}

The hydro-meteorological observations data, which are sent to data management system, needs to be checked. This observation can be used for any services when it has been checked and the quality of the data is reliable. In FNEP, a special emphasis has been put to improve the data management system and quality control of the data. The data management system includes several high quality components. For example, the automatic quality control module scans received data and applies various quality control mechanisms to guarantee the high quality of the data (Keränen and Partio, 2012).

The data management system provides solid foundation for any future development. The system is developed in such a way that it can easily support tens or even hundreds of real time automatic weather stations. It also enables 
the migrating of hydrological data into the same database with automatic quality control. The data management system can also be extended to handle new data types like soundings, lightning location data, and weather model data. It also enables an extension to the development of new weather products: new internet-based products, products for radio, newspapers, aviation, other governmental agencies etc.

\subsection{Early warning strategy}

The previously mentioned socio economic scan, hydro-meteorological observations, data management, and quality control form an important basis for weather services. To be able to serve the society and every single citizen in Nepal, a common early warning strategy is needed (Tourula et al., 2012). Weather and weather related hazards have a severe impact on Nepalese society. As an example, the activities of the following sectors are affected: public, agriculture, health, aviation, energy, water supply, education, communication, and tourism. Within Nepal, the preparedness for natural disasters and resilience to the climate change can be improved by establishing a multi-hazard early warning centre for hydro-meteorological phenomena. In the preparedness phase, a reliable and precise Early Warning System (EWS) is essential from the community level to the central government level. Information about weather, water and climate-related hazards should be provided from a single source. In the 5-year plan for DHM EWS prepared during the FNEP -project, it is suggested that one operational hydro-meteorological centre would act as an Early Warning Centre (EWC). The DHM multihazard EWS is based on and integrated within reliably functioning forecasting system of the DHM, which should be in operation 24 hours a day, seven days a week. The EWS should also include a communication and dissemination system that ensures that forecasts and warnings are received by various user groups, including public, through clear protocols and procedures that are regularly tested, evaluated and maintained. The planning scheme for the EWS includes training and capacity-building to use the weather, climate and water-related information and work processes, which are required to operate the EWS in DHM. Active cooperation and feedback mechanisms between the national service and user groups facilitate the evaluation and improvement of the warning system.

\subsection{Stakeholder involvement}

Two workshops were arranged during the project. The first one was a regional workshop in February 2011 termed as "Improvement of Weather Services for the Societal Development in Nepal". This was actually the first of a kind workshop ever arranged in Nepal to gather both national and international participants to discuss weather forecasting and information needs in different sectors of the society. The second workshop, "Achievements and Opportunities to Respond the Weather and Climate related Challenges in Nepal - now and future", took place in April 2012, in Kathmandu, Nepal. This workshop was arranged to share the information about the results of FNEP project and also to gather future development needs of stakeholders to the weather services. Both workshops gathered 80-100 participants.

The FNEP project published of two informative short TV programs regarding climate change and its effects, targeted to the general public of Nepal. The latter one broadcasted in April, 2012 is available in youtube at http://www.youtube. $\operatorname{com} /$ watch? $\mathrm{v}=$ _hbKnJQ0GIc\&feature=youtu. be.

\section{DISCUSSION AND CONCLUSIONS}

The study tours in FMI and FMI expert 
missions to Nepal under this project provided valuable information to DHM professionals by the exchange of ideas and views on latest trend of technological development and available technologies in FMI and possibilities to transfer the technology in the development of meteorological service in Nepal. The areas of interest emphasize mostly on data management system and functioning mechanism, instrument calibration and quality control procedure, weather services and products, observations, climate monitoring and climate change study, early warning system for natural hazards etc. One of the great achievements of the project for DHM is the establishment of a real time data base management system with quality control procedure. Finland is one of the least vulnerable countries in terms of natural disasters but their early warning system (EWS) is one of the most advanced in the world. Nepal somehow lags behind in early warning system, so a fiveyear plan for DHM early warning system is a valuable achievement for establishing a wellfunctioning EWS at DHM in the near future.

The first step in the improvement to increase DHM capacity in hydro-meteorological observations, services and international data sharing have been taken into account in this project. Workshops arranged during FNEP have served the meteorological society as one tool of the data sharing and cooperation. But to be able to develop the services and the data sharing further the national and international cooperation is important and should continue. The cooperation and coordination with different ministries such as energy, aviation, agriculture, health etc. and international organizations such as UNDP, SAARC, ICIMOD and projects such as PPCR is of utmost necessary. By putting our forces and hands together, we will receive the results faster and better.

\section{REFERENCES}

Keränen, M., and M. Partio, 2012: FNEP Mission No 12 Report. FMI FNEP Reports, 2012.

Perrels, A., 2011: Social economic benefits of enhanced weather services in Nepal. FMI FNEP Reports 2011.

Poutiainen, J., P. Rissanen, and I. Ylikangas, 2011: Overview of the Nepal Weather Network 5-year plan. FMI FNEP Reports, 2011.

Tourula, T., K. Jäntti, K.P. Budhathoki, D. Gautam, and M.R. Shakya, 2012: 5-Year Plan for DHM Early Warning System (EWS). FMI FNEP Reports, 2012.

Malla, G., 2008: Climate change and its impact on Nepalese agriculutre. The Journal of Agriculture and Environment, 9.

Xu, J., R.E. Grumbine, A. Shrestha, M. Eriksson, X. Yang, Y. Wang, and A. Wilkes, 2009: The Melting Himalayas: Cascading Effects of Climate Change on Water, Biodiversity, and Livelihoods. Conservation Biology, 23, 520530. 